\title{
Resveratrol and pterostilbene: A comparative overview of their chemistry, biosynthesis, plant sources and pharmacological properties
}

\author{
Eric Wei Chiang Chan ${ }^{1 *}$, Chen Wai Wong ${ }^{1}$, Yong Hui Tan ${ }^{1}$, Jenny Pei Yan Foo ${ }^{1}$, Siu Kuin Wong'2, Hung Tuck Chan ${ }^{3}$ \\ ${ }^{1}$ Faculty of Applied Sciences, UCSI University, Kuala Lumpur, Malaysia. \\ ${ }^{2}$ School of Science, Monash University Sunway, Selangor, Malaysia. \\ ${ }^{3}$ Secretariat, International Society for Mangrove Ecosystems (ISME), Faculty of Agriculture, University of the Ryukyus, Okinawa, Japan.
}

\section{ARTICLE INFO \\ Received on: 31/01/2019 \\ Accepted on: 10/04/2019 \\ Available online: 01/07/2019}

Key words:

Resveratrol, pterostilbene, pharmacology, pharmacokinetics, future research.

\begin{abstract}
Both resveratrol and pterostilbene are monomeric stilbenes having a 6-2-6 carbon skeleton with two phenyl rings linked by a double-bonded ethylene bridge. Resveratrol has three hydroxyl $(-\mathrm{OH})$ groups, while pterostilbene has two methoxy $\left(-\mathrm{OCH}_{3}\right)$ groups and one $-\mathrm{OH}$ group. They commonly occur in the trans form rather than the cis form. Red grapes and red wines are the main dietary sources of the resveratrol. Pterostilbene occurs in blueberries and grapes. Resveratrol and pterostilbene exhibit many similarities in pharmacological properties, including antioxidant, neuroprotective anti-cancer, cardioprotective, analgesic, anti-atherosclerosis, anti-aging, anti-diabetic, antiinflammatory, and anti-obesity activities. The stronger pharmacological properties in pterostilbene than resveratrol have been attributed to its two $-\mathrm{OCH}_{3}$ groups. As a result, pterostilbene is more lipophilic which enhances its membrane permeability, bioavailability, and biological potency. Some future studies on resveratrol and pterostilbene are suggested. The sources of information cited in this comparative overview were from Science Direct, Google Scholar, and PubMed.
\end{abstract}

\section{INTRODUCTION}

Stilbenes are phenolic compounds having two aromatic rings with $-\mathrm{OH}$ groups and are linked by a double-bonded ethylene bridge (Akinwumi et al., 2018; El Khawand et al., 2018). Found in higher plants, stilbenes exist as monomeric, dimeric, trimeric, oligomeric, and polymeric forms, or as glycosides. Stilbenes possess biological activities, such as anti-diabetic, antiobesity, cardioprotective, neuroprotective, anti-inflammatory, anti-atherosclerosis, and anti-cancer properties (Akinwumi et al., 2018). Resveratrol and pterostilbene represent two of the

\footnotetext{
${ }^{*}$ Corresponding Author

Eric Wei Chiang Chan, Faculty of Applied Sciences, UCSI University,

Kuala Lumpur, Malaysia.

E-mail: chanwc@ucsiuniversity@edu.my; erchan@yahoo.com
}

monomeric stilbenes with well-studied biological activities and molecular effects (Tsai et al., 2017).

It was reported that the consumption of red wine in France has cardioprotective effects and reduces the risk of cardiovascular diseases (Renaud and de Lorgeril, 1992). The low occurrence of coronary heart diseases among the French people, despite their high-fat diet, is popularly known as the French paradox (Sun et al., 2002). These health benefits of red wine have been attributed to resveratrol (Siemann and Creasy, 1992). Since then, much research was conducted on the cardioprotective and other medicinal properties of resveratrol, a major compound of red grapes and red wine (Catalgol et al., 2012). Pharmacological activities of resveratrol include cardioprotective (Hsieh and $\mathrm{Wu}$, 2018), antioxidant (Cavallini et al., 2016), anti-inflammatory (de Sả Coutinho et al., 2018), anti-atherosclerosis (Bonnefont-Rousselot, 2016), anti-aging (Bhullar and Hubbard, 2015; Li et al., 2018), anti-diabetic (Szkudelski and Szkudelska, 2011), 
anti-osteoporosis (Tou et al., 2015), and anti-obesity (de Ligt et al., 2015; Pan et al., 2018) properties.

Among the many pharmacological activities of resveratrol (Baur and Sinclair, 2006; Berman et al., 2017), its anticancer properties are most well-known. Since its first report by Jang et al. (1997), there are many reviews on the subject (Rauf et al., 2018; Varoni et al., 2016). Displaying various molecular mechanisms, resveratrol has shown to be a promising and multitarget agent for cancer prevention and treatment.

In recent years, the neuroprotective effects of resveratrol have also gained much research interest. The overall health benefits of resveratrol toward age-related diseases have become a topic of intense investigations (Timmers et al., 2012). Reviews on the neuroprotective properties of resveratrol are mostly agerelated neurodegenerative disorders related to Alzheimer's disease and Parkinson's disease (Tellone et al., 2015), brain degeneration (Poulose et al., 2015), and neurological disorders, such as stroke and CNS injury (Lopez et al., 2015). Currently, there is one comprehensive review by Bastianetto et al. (2015) that summarized recent findings on the molecular mechanisms of action and discussed possible roles of resveratrol in the prevention of various neurological disorders.

Pterostilbene was reported by Remsberg et al. (2008) to have anti-cancer, anti-inflammatory, antioxidant, and analgesic effects on rats. These findings generated much research excitement in pterostilbene and subsequently, properties, such as anti-cancer (McCormack and Mc Fadden, 2012; Nutakul et al., 2011), antiinflammatory (Dvorakova and Landa, 2017), neuroprotective (Poulose et al., 2015; Wang et al., 2016), anti-obesity (Aguirre et al., 2016; Pan et al., 2018), anti-diabetic (Tastekin et al., 2018), antioxidant (McCormack and McFadden, 2013; Rimando et al., 2002), anxiolytic (Al Rahim et al., 2013), and anti-aging (Li et al., 2018) activities have been documented. Recently, the promising therapeutic potential of pterostilbene and its mechanistic insight based on recent preclinical evidence was reviewed by Kosuru et al. (2016).

This comparative overview on the pharmacological properties of resveratrol and pterostilbene is appropriate and timely as the surge in the number of research studies in recent years has generated a wealth of new knowledge. Such useful information will set the platform for scientists to conduct further research on resveratrol, pterostilbene, and other derivatives. References cited in this overview were procured from databases downloaded from Science Direct, Google Scholar, and PubMed.

\section{CHEMISTRY}

Resveratrol or trans-3,4',5-trihydroxystilbene is a monomer stilbene with a molecular formula of $\mathrm{C}_{14} \mathrm{H}_{12} \mathrm{O}_{3}$ and a molecular weight of $228.25 \mathrm{~g} / \mathrm{mol}$. The molecule has two aromatic rings, linked by an ethylene bridge with an ethene double bond (Fig. 1). Ring A has two hydroxyl (-OH) groups at $\mathrm{C} 3$ and $\mathrm{C} 5$, and ring $\mathrm{B}$ has one $-\mathrm{OH}$ group at $\mathrm{C}^{\prime}$ ' (Tsai et al., 2017). Resveratrol has a 6-2-6 carbon skeleton with m-hydroquinone and 4'-hydroxystyryl moieties involving rings $\mathrm{A}$ and $\mathrm{B}$, respectively (Niesen et al., 2013).

In food products, resveratrol commonly occurs in the trans form rather than in the cis form (Anisimova et al., 2011). When resveratrol is exposed to ultraviolet and visible light, trans to cis isomerization occurs (Silva et al., 2013). The rarer cis-resveratrol is less stable and is not commercially available (Cottart et al., 2010). Red wine is rich in trans-resveratrol, and its moderate consumption has health benefits of lower rates of prostate cancer (Schoonen et al., 2005). Against PC-3 prostate cancer cells, trans-resveratrol was reported to be a more effective anti-cancer agent than cis-resveratrol and dihydro-resveratrol (Anisimova et al., 2011). Earlier, trans-resveratrol has been reported to be 10 times more potent in inducing apoptosis of HL60 leukemia cells as compared to cis-resveratrol (Roberti et al., 2003).

Pterostilbene or trans-3,5-dimethoxy-4'-hydroxystilbene has a molecular formula of $\mathrm{C}_{16} \mathrm{H}_{16} \mathrm{O}_{3}$, molecular weight of 256.30 $\mathrm{g} / \mathrm{mol}$ (Kosuru et al., 2016; McCormack and Mc Fadden, 2012; Tsai et al., 2017). Its other names are dimethoxy resveratrol, 3,5'-dimethoxy-4-stilbenol and 4-[2-(3,5-dimethoxyphenyl) ethenyl] phenol. Being a dimethylated analog of resveratrol, pterostilbene is structurally similar to resveratrol by having one hydroxyl group at $\mathrm{C}^{\prime}$ ' of ring $\mathrm{B}$ but differs by having two $-\mathrm{OCH}_{3}$ groups at $\mathrm{C} 3$ and $\mathrm{C} 5$ of ring $\mathrm{A}$ (Fig. 2). Like resveratrol, the trans form of pterostilbene is more abundant than the cis form (Kosuru et al., 2016).

\section{BIOSYNTHESIS AND PLANT SOURCES}

In plants, the biosynthesis of resveratrol and pterostilbene shares similar substrates and biosynthetic pathway as flavonoids (Jeandet et al., 2010; Poulose et al., 2015). Unlike flavonoids which are produced by most plants, only a few plant species synthesize these stilbenes. The biosynthetic pathway of resveratrol begins with phenylalanine of the shikimate pathway, which undergoes various enzymatic reactions to produce p-coumaroyl-CoA. In the presence of malonyl-CoA and stilbene synthase, trans-resveratrol is produced via an aldol reaction. Trans-resveratrol is then converted to pterostilbene by $O$-methyl transferase.

Resveratrol was first isolated from the roots of Veratrum grandiflorum and later from the roots of Polygonum cuspidatum (Nonomura et al., 1963). From P. cuspidatum, an important traditional medicine in China, the content of resveratrol has been reported to be $1.8 \mathrm{mg} / \mathrm{g}$ (Zhao et al., 2005). The compound has been isolated from more 70 plant species, including grapes and red wine (Rege et al., 2014). Red grapes and red wine, as shown in Figure 3, are the main dietary sources of resveratrol. Red grapes

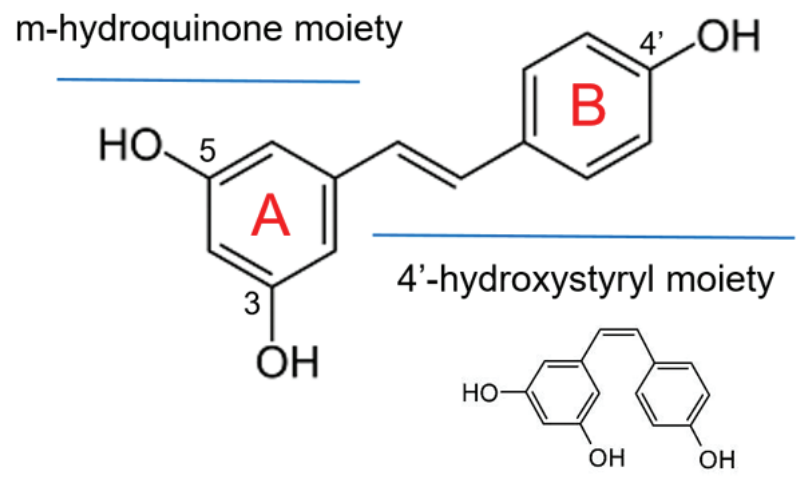

Figure 1. The molecular structures of trans-resveratrol with cis-resveratrol as inset. 
contain mainly of piceid $(1.5-7.3 \mu \mathrm{g} / \mathrm{g})$, while red wine is rich in resveratrol (1.0-18 $\mu \mathrm{g} / \mathrm{ml})$ (Burns et al., 2002). From the skin of grapes, the content of resveratrol ranged from 2.48 to $6.47 \mu \mathrm{g} / \mathrm{g}$ (Rimando et al., 2004). The concentration of trans-resveratrol in red wine is six times higher than in white wine, which contains high levels of cis-resveratrol (Rege et al., 2014). A possible explanation is that red wine is produced without removing the skin of grapes, whereas white wine is fermented after the removal of the skin.

Pterostilbene was first isolated from Pterocarpus santalinus (sandalwood) in 1940 (Seshadri, 1972), and later identified in Vitis vinifera (grape vine) (Adrian et al., 2000; Langcake et al., 1979), Pterocarpus marsupium (Indian kino) (Manickam et al., 1997; Maurya et al., 1984), Vaccinium berries (Rimando et al., 2004), and Arachis hypogaea (peanut) (Sobolev et al., 2011).

\section{PHARMACOLOGICAL PROPERTIES}

Resveratrol and pterostilbene exhibit many similarities in pharmacological properties (Akinwumi et al., 2018; Tsai et al., 2017; Wang and Sang, 2018). They include antioxidant, neuroprotective anti-cancer, cardioprotective, analgesic, anti-atherosclerosis, antiaging, anti-diabetic, anti-inflammatory, and anti-obesity activities.

Studies have shown that both resveratrol and pterostilbene are able to cross the blood-brain barrier and influence brain activity (Lange and Lee, 2017). The blood-brain barrier is a diffusion barrier essential for the normal functioning of the central nervous system. Located at the capillaries between the blood and cerebral tissue, the blood-brain barrier has endothelial cells with tight junctions that impede the influx of most blood-borne compounds from entering the brain (Ballabh et al., 2004; Kanwar et al., 2012). Small lipophilic molecules, such as oxygen $\left(\mathrm{O}_{2}\right)$ and carbon dioxide $\left(\mathrm{CO}_{2}\right)$, can diffuse through plasma membranes while nutrients, such as glucose and amino acids, and larger molecules, including insulin, leptin, and iron transferrin, enter the brain via transporters and receptormediated endocytosis, respectively. The blood-brain barrier has been reported to prevent $98 \%$ of small molecules and $100 \%$ of large molecules from reaching the brain (Kanwar et al., 2012).

A study by Wang et al. (2002) demonstrated that the resveratrol can cross the blood-brain barrier and protects

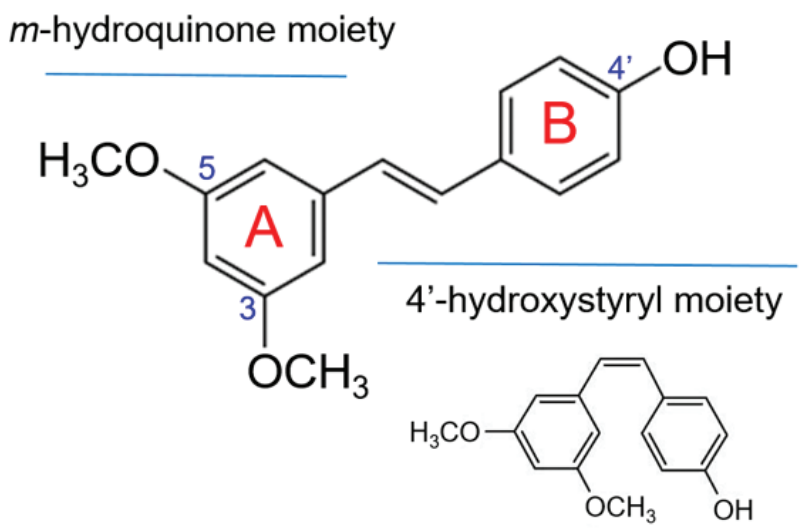

Figure 2. The molecular structures of trans-pterostilbene with cis-pterostilbene as inset. against cerebral ischemic injury in gerbils. The study noted that after injection into these animals, resveratrol rapidly enters the bloodstream as glucuronide conjugate, crosses the blood-brain barrier, and is subsequently enters the brain tissue. Resveratrol was retained in the brain for up to 4 hours.

Although there are structural and bioactivity similarities between resveratrol and pterostilbene, pharmacological properties of pterostilbene are often stronger than those of resveratrol (Table 1).

The stronger pharmacological properties in pterostilbene than resveratrol have been attributed to the dimethoxy groups at C3 and C5 of ring A (Fig. 2). With these structural characteristics, pterostilbene is more lipophilic, enhancing its membrane permeability, bioavailability, and bioactivity (Kapetanovic et al., 2011; McCormack and Mc Fadden, 2012; Wang and Sang, 2018). Overall, pterostilbene performs better in membrane permeability and metabolic stability than resveratrol. This increases the bioavailability, and enhances the pharmacokinetic profile and pharmacological activities of pterostilbene.

Studies have shown that both resveratrol and pterostilbene are safe for human consumption. In a clinical trial conducted on 40 healthy volunteers, resveratrol was found to be safe after daily doses of $0.5,1.0,2.5$, and $5.0 \mathrm{~g}$ for 29 days, with the exception of 2.5 and $5.0 \mathrm{~g}$ doses which caused some gastrointestinal discomfort (Brown et al., 2010). In two studies, 28 daily doses of 50,150 , or $500 \mathrm{mg} /$ $\mathrm{kg}$ body weight, and 90 daily dose of $700 \mathrm{mg} / \mathrm{kg}$ body weight of Resvida $^{\mathrm{TM}}$ (high-purity resveratrol) did not have any adverse effects on rats (Williams et al., 2009). For pterostilbene, a clinical trial (randomized, double-blind, and placebo-controlled) conducted in 80 healthy volunteers for 6-8 weeks, demonstrated that the pterostilbene is generally safe for consumption at doses of up to $250 \mathrm{mg} /$ day (Riche et al., 2013). Biochemical analysis showed that the pterostilbene had no adverse reactions on liver, kidney, and glucose markers.

Kapetanovic et al. (2011) reported that there was greater oral absorption and cellular uptake of pterostilene in rats than resveratrol. One of the studies indicated that the pterostilbene (orally administered) displayed 95\% bioavailability, as compared to resveratrol with only $20 \%$ bioavailability. In addition, the halflife of resveratrol in the blood was found to be 14 minutes (Asensi et al., 2002), whereas pterostilbene with two $-\mathrm{OCH}_{3}$ groups had
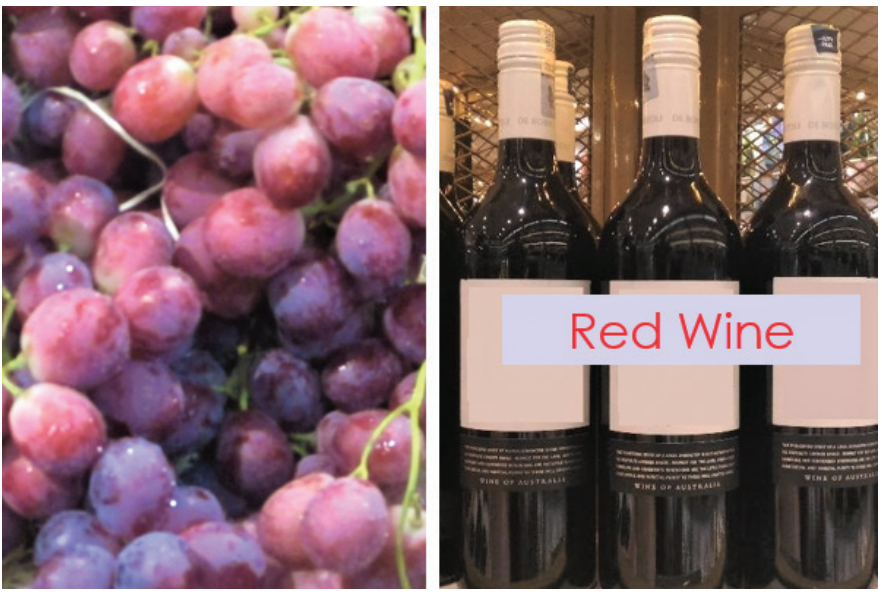

Figure 3. Red grapes (left) and red wine (right). 
Table 1. Comparative pharmacological properties of pterostilbene (PS) and resveratrol (RV).

\begin{tabular}{|c|c|c|}
\hline Activity & Pharmacological property & Reference \\
\hline Anti-cancer & $\begin{array}{l}\text { Against HT-29 human colon cancer cells, PS }\left(\mathrm{IC}_{50}=22.4 \mu \mathrm{mol} / \mathrm{l}\right) \text { was a more potent inhibitor of proliferation when compared } \\
\text { with resveratrol }\left(\mathrm{IC}_{50}=43.8 \mu \mathrm{mol} / \mathrm{l}\right) \text {. }\end{array}$ & (Paul et al., 2009) \\
\hline Anti-cancer & $\begin{array}{l}\text { PS displayed stronger growth inhibitory activities than RV against HT-29, HCT-116 and Caco- } 2 \text { human colon cancer cells. With } \\
\mathrm{IC}_{50} \text { values of } 15,12 \text {, and } 75 \mu \mathrm{M} \text {, PS was } 4.3,2.1 \text {, and }>1.3 \text { times stronger than RV, respectively. }\end{array}$ & (Nutakul et al., 2011) \\
\hline Anti-cancer & $\begin{array}{l}\text { Against HeLa human cervical cancer cells, the cytotoxicity of PS }\left(\mathrm{IC}_{50}=42.3 \mu \mathrm{M}\right) \text { was almost two times that of } \mathrm{RV} \\
\left(\mathrm{IC}_{50}=83.5 \mu \mathrm{M}\right) .\end{array}$ & (Chatterjee et al., 2018) \\
\hline Antioxidant & PS protected human erythrocytes against lipid peroxidation with $\mathrm{IC}_{50}$ value of $44.5 \mu \mathrm{M}$. RV was significantly less effective. & (Mikstacka et al., 2010) \\
\hline Antioxidant & $\begin{array}{l}\text { Against mammalian cells with oxidative DNA damage induced by hydrogen peroxide }\left(\mathrm{H}_{2} \mathrm{O}_{2}\right) \text {, results on the protective effects } \\
\text { of RV and PS showed the strongest inhibition in PS }(85.5 \%) \text { followed by RV }(21.1 \%) \text {. }\end{array}$ & (Rossi et al., 2013) \\
\hline Neuroprotective & $\begin{array}{l}\text { Among } 21 \text { resveratrol derivatives tested for their inhibitory effects on lipopolysaccharide-induced nitric oxide (NO) production } \\
\text { in microglia, the strongest activity was observed in PS }\left(\mathrm{IC}_{50} \text { value of } 1.9 \mu \mathrm{M}\right) \text {. Its } \mathrm{IC}_{50} \text { value was } 8.2 \text { times stronger than } \mathrm{RV} \\
\left(\mathrm{IC}_{50} \text { value of } 15.5 \mu \mathrm{M}\right) \text {. }\end{array}$ & (Meng et al., 2012) \\
\hline Neuroprotective & $\begin{array}{l}\text { In mice, PS is a more potent neuro-modulator of cognition function and cellular stress than RV, suggesting that PS can be used } \\
\text { as a drug to improve cognitive function in aging and to slow down the progress of Alzheimer's disease. }\end{array}$ & (Chang et al., 2012) \\
\hline Anti-diabetic & PS is relatively more effective than RV in improving the metabolic parameters of streptozotocin-induced diabetic rats. & (Tastekin et al., 2018) \\
\hline Hypolipidemic & $\begin{array}{l}\text { PS is more potent as an agonist of peroxisome proliferator-activated receptor alpha, and as a stronger hypolipidemic and } \\
\text { glucose-lowering agent than RV. }\end{array}$ & (Rimando et al., 2005) \\
\hline Anti-inflammatory & Anti-inflammatory activities of PS were stronger than RV when assessed using human subjects with rheumatoid arthritis. & (Choo et al., 2014) \\
\hline Anti-platelet aggregation & Both RV and PS strongly inhibited platelet aggregation, and stimulated NO production in platelets. & (Messina et al., 2015) \\
\hline Anti-androgenic & $\begin{array}{l}\text { Among the analogs of RV tested, PS exhibited the strongest anti-androgenic activity. Its hydrogen bonding interactions pattern } \\
\text { and binding energy resembled that of anti-androgenic flutamide. }\end{array}$ & (Chakraborty et al., 2014) \\
\hline Antifungal & $\begin{array}{l}\text { PS was 5-10 times more effective than RV in inhibiting the germination of Botrytis cinerea conidia and Plasmopara viticola } \\
\text { sporangia. }\end{array}$ & (Jeandet et al., 2002) \\
\hline Bioavailability & $\begin{array}{l}\text { The half-life of PS in rat serum was } 1.73 \text { hours, while those of RV and RV glucuronide } 1.31 \text { and } 1.52 \text { hours in rat plasma, } \\
\text { respectively. The half-life of RV was only } 0.24 \text { hours in rabbit plasma. The significantly longer half-life of PS can be translated } \\
\text { into greater bioavailability. }\end{array}$ & $\begin{array}{l}\text { (Asensi et al., 2002; } \\
\text { Remsberg et al., 2008) }\end{array}$ \\
\hline Bioavailability & $\begin{array}{l}\text { Higher oral bioavailability was observed in PS }(80 \%) \text { vs. RV (20\%) of rats. Following oral administration, plasma levels of PS } \\
\text { and PS sulfate were markedly higher than those of RV and RV sulfate. }\end{array}$ & (Kapetanovic et al., 2011) \\
\hline Pharmacokinetics & $\begin{array}{l}\text { Following equimolar dose administration to rats, PS displayed superior pharmacokinetic profile than RV. The oral } \\
\text { bioavailability of PS }(67 \%) \text { was } 2.2 \text { times that of RV }(30 \%) \text {. }\end{array}$ & (Kapetanovic et al., 2011) \\
\hline Pharmacokinetics & $\begin{array}{l}\text { RV and PS were mainly excreted as metabolites in the faeces (non-renal) and not in the urine (renal), suggesting the importance } \\
\text { of enterohepatic cycling in their metabolism. }\end{array}$ & $\begin{array}{l}\text { (Marier et al., 2002; } \\
\text { Remsberg et al., 2008) }\end{array}$ \\
\hline
\end{tabular}

a half-life of 105 minutes or seven times longer than resveratrol (Remsberg et al., 2008).

\section{CONCLUSION}

Future research on the pharmacological properties of resveratrol and pterostilbene would focus on elucidating a better understanding the mechanisms of action involved. The overall health benefits of resveratrol and pterostilbene will continue to be topics of intense investigation. In addition, further studies on various aspects of metabolism, absorption, bioavailability, pharmacokinetics, biotransformation, structureactivity relationships, dose-response, synergism, and side-effects of resveratrol and pterostilbene are warranted. Overall, research findings on the mechanisms and health benefits of resveratrol and pterostilbene in humans need to be confirmed via more detailed and convincing clinical trials. It is acknowledged that clinical trials of resveratrol and pterostilbene are at the cross-road of establishing human evidence from in vitro and in vivo information. Resveratrol and pterostilbene molecules could be used as the scaffold for producing synthetic compounds with enhanced pharmaceutical attributes and other added-values. The prospects of developing resveratrol and pterostilbene into nutritional and/or pharmacological biomolecules for use as multi-target therapeutic drugs are indeed promising.

\section{ACKNOWLEDGMENTS}

The authors would like to thank the UCSI University (Proj-In-FAS-043; Proj-In-FAS-049) and University Malaya (PG153-2014B) for supporting the research group.

\section{CONFLICT OF INTEREST}

Authors declare that there is no conflict of interest.

\section{REFERENCES}

Adrian M, Jeandet P, Douillet-Breuil AC, Tesson L, Bessis R. Stilbene content of mature Vitis vinifera berries in response to UV-C elicitation. J Agric Food Chem, 2000; 48:6103-5.

Aguirre L, Milton-Laskibar I, Hijona E, Bujanda L, Rimando AM, Portillo MP. Effects of pterostilbene in brown adipose tissue from obese rats. J Physiol Biochem, 2016; 73:457-64.

Akinwumi B, Bordun KA, Anderson H. Biological activities of stilbenoids. Int J Mol Sci, 2018; 19:792.

Al Rahim M, Rimando AM, Silistreli K, El-Alfy AT. Anxiolytic action of pterostilbene: involvement of hippocampal ERK phosphorylation Planta Med, 2013; 79:723-30.

Anisimova NY, Kiselevsky MV, Sosnov AV, Sadovnikov SV, Stankov IN, Gakh AA. Trans-, cis- and dihydro-resveratrol: a comparative study. Chem Central J, 2011; 5:88.

Asensi M, Medina I, Ortega A, Carretero J, Baño MC, Obrador E, Estrela JM. Inhibition of cancer growth by resveratrol is related to its low bioavailability. Free Radic Biol Med, 2002; 33:387-98. 
Ballabh P, Braun A, Nedergaard M. The blood-brain barrier: an overview-structure, regulation and clinical implications. Neurobiol Dis, 2004; 16:1-3.

Bastianetto S, Ménard C, Quirion R. Neuroprotective action of resveratrol. Biochim Biophys Acta-Mol Basis Dis, 2015; 1852: 1195-201.

Baur JA, Sinclair DA. Therapeutic potential of resveratrol: the in vivo evidence. Nat Rev Drug Discov, 2006; 5:493-506.

Berman AY, Motechin RA, Wiesenfeld MY, Holz MK. The therapeutic potential of resveratrol: a review of clinical trials. NPJ Precis Oncol, 2017; 1:35.

Bhullar KS, Hubbard BP. Lifespan and health-span extension by resveratrol. Biochim Biophys Acta-Mol Basis Dis, 2015; 1852:1209-18.

Bonnefont-Rousselot D. Resveratrol and cardiovascular diseases. Nutrients, 2016; 8:250.

Brown VA, Patel KR, Viskaduraki M, Crowell JA, Perloff M, Booth TD, Vasilinin G, Sen A, Schinas AM, Piccirilli G, Brown K. Repeat dose study of the cancer chemopreventive agent resveratrol in healthy volunteers: safety, pharmacokinetics, and effect on the insulin-like growth factor axis. Cancer Res, 2010; 70:9003-11.

Burns J, Yokota T, Ashihara H, Lean MEJ, Crozier A. Plant foods and herbal sources of resveratrol. J Agric Food Chem, 2002; 50:3337-40.

Catalgol B, Batirel S, Taga Y, Ozer NK. Resveratrol: French paradox revisited. Front Pharmacol, 2012; 3:141

Cavallini G, Straniero S, Donati A, Bergamini E. Resveratrol requires red wine polyphenols for optimum antioxidant activity. J Nutr Health Aging, 2016; 20:540-5.

Chakraborty S, Kumar A, Butt NA, Zhang L, Williams R, Rimando AM, Biswas PK, Levenson AS. Molecular insight into the differential antiandrogenic activity of resveratrol and its natural analogs: in silico approach to understand biological actions. Mol BioSyst, 2016; 12:1702-9.

Chang J, Rimando A, Pallas M, Camins A, Porquet D, Reeves J, Shukitt-Hale B, Smith MA, Joseph JA, Casadesus G. Low-dose pterostilbene, but not resveratrol, is a potent neuro-modulator in aging and Alzheimer's disease. Neurobiol Aging, 2012; 33:2062-71.

Chatterjee K, AlSharif D, Mazza C, Syar P, Al Sharif M, Fata JE. Resveratrol and pterostilbene exhibit anticancer properties involving the downregulation of HPV oncoprotein E6 in cervical cancer cells. Nutrients, 2018; 10:243

Choo QY, Yeo SC, Ho PC, Tanaka Y, Lin HS. Pterostilbene surpassed resveratrol for anti-inflammatory application: potency consideration and pharmacokinetics perspective. J Funct Foods, 2014; 11:352-62.

Cottart CH, Nivet-Antoine V, Laguillier-Morizot C, Beaudeux JL. Resveratrol bioavailability and toxicity in humans. Mol Nutr Food Res, 2010; 54:7-16.

de Ligt M, Timmers S, Schrauwen P. Resveratrol and obesity: can resveratrol relieve metabolic disturbances? Biochim Biophys ActaMol Basis Dis, 2015; 1852:1137-44.

de Sá Coutinho D, Pacheco M, Frozza R, Bernardi A. Antiinflammatory effects of resveratrol: mechanistic insights. Int J Mol Sci, 2018; 19:1812.

Dvorakova M, Landa P. Anti-inflammatory activity of natural stilbenoids: a review. Pharmacol Res, 2017; 124:126-45.

El Khawand T, Courtois A, Valls J, Richard T, Krisa S. A review of dietary stilbenes: sources and bioavailability. Phytochem Rev, 2018; 17:1007-29.

Langcake P, Cornford CA, Pryce RJ. Identification of pterostilbene as a phytoalexin from Vitis vinifera leaves. Phytochemistry, $1979 ; 18: 1025-7$.

Hsieh TC, Wu JM. 2018. Unraveling and trailblazing cardioprotection by resveratrol. In: Wu JM, Hsieh TC, editors. Resveratrol: State-of-the-Art Science and Health Applications. World Publishing, Singapore, pp. 1-28, 2018.

Jang M, Cai L, Udeani GO, Slowing KV, Thomas CF, Beecher CW, Fong HH, Farnsworth NR, Kinghorn AD, Mehta RG, Moon RC.
Cancer chemopreventive activity of resveratrol, a natural product derived from grapes. Science, 1997; 275:218-20.

Jeandet P, Delaunois B, Conreux A, Donnez D, Nuzzo V, Cordelier S, Clément C, Courot E. Biosynthesis, metabolism, molecular engineering, and biological functions of stilbene phytoalexins in plants. Biofactors, 2010; 36:331-41.

Jeandet P, Douillet-Breuil AC, Bessis R, Debord S, Sbaghi M, Adrian M. Phytoalexins from the Vitaceae: biosynthesis, phytoalexin gene expression in transgenic plants, antifungal activity, and metabolism. J Agric Food Chem, 2002; 50:2731-41.

Kanwar JR, Sriramoju B, Kanwar RK. Neurological disorders and therapeutics targeted to surmount the blood-brain barrier. Int $\mathrm{J}$ Nanomed, 2012; 7:3259-78.

Kapetanovic IM, Muzzio M, Huang Z, Thompson TN, McCormick DL. Pharmacokinetics, oral bioavailability, and metabolic profile of resveratrol and its dimethylether analog, pterostilbene, in rats. Cancer Chemother Pharmacol, 2011; 68:593-601.

Kosuru R, Rai U, Prakash S, Singh A, Singh S. Promising therapeutic potential of pterostilbene and its mechanistic insight based on preclinical evidence. Eur J Pharmacol, 2016; 789:229-43.

Lange $\mathrm{KW}$, Li S. Resveratrol, pterostilbene, and dementia. BioFactors, 2018; 44:83-90.

Li YR, Li S, Lin CC. Effect of resveratrol and pterostilbene on aging and longevity. Biofactors, 2018; 44:69-82.

Lopez MS, Dempsey RJ, Vemuganti R. Resveratrol neuroprotection in stroke and traumatic CNS injury. Neurochem Int, 2015; 89:75-82.

Manickam M, Ramanathan M, Jahromi MA, Chansouria JP, Ray AB. Anti-hyperglycemic activity of phenolics from Pterocarpus marsupium. J Nat Prod, 1997; 60:609-10.

Marier JF, Vachon P, Gritsas A, Zhang J, Moreau JP, Ducharme MP. Metabolism and disposition of resveratrol in rats: extent of absorption, glucuronidation, and enterohepatic recirculation evidenced by a linked-rat model. J Pharmacol Exper Ther, 2002; 302:369-73.

Maurya R, Ray AB, Duah FK, Slatkin DJ, Schiff PL. Constituents of Pterocarpus marsupium. J Nat Prod. 1984; 47:179-81.

McCormack D, McFadden D. Pterostilbene and cancer: current review. J Surg Res, 2012; 173:53-61.

McCormack D, McFadden D. A review of pterostilbene antioxidant activity and disease modification. Oxid Med Cell Longev, 2013; Article ID 575482, $15 \mathrm{p}$.

Meng XL, Yang JY, Chen GL, Wang LH, Zhang LJ, Wang S, Li J, Wu CF. Effects of resveratrol and its derivatives on lipopolysaccharideinduced microglial activation and their structure-activity relationships. Chem Biol Interact, 2008; 174:51-9.

Messina F, Guglielmini G, Curini M, Orsini S, Gresele P, Marcotullio MC. Effect of substituted stilbenes on platelet function. Fitoterapia, 2015; 105:228-33.

Mikstacka R, Rimando AM, Ignatowicz E. Antioxidant effect of trans-resveratrol, pterostilbene, quercetin and their combinations in human erythrocytes in vitro. Plant Foods Hum Nutr, 2010; 65:57-63.

Niesen DB, Hessler C, Seeram NP. Beyond resveratrol: a review of natural stilbenoids identified from 2009-2013. J Berry Res, 2013; 3 : $181-96$.

Nonomura S, Kanagawa H, Makimoto A. Chemical constituents of polygonaceous plants. I. Studies on the components of Ko-jo-kon (Polygonum cuspidatum Sieb. et Zucc.). Yakugaku Zasshi, 1963; 83: 988-90.

Nutakul W, Sobers HS, Qiu P, Dong P, Decker EA, McClements DJ, Xiao H. Inhibitory effects of resveratrol and pterostilbene on human colon cancer cells: a side-by-side comparison. J Agric Food Chem, 2011; 59:10964-70

Pan MH, Wu JC, Ho CT, Lai CS. Anti-obesity molecular mechanisms of action: resveratrol and pterostilbene. BioFactors, 2018, 44:50-60. 
Paul S, Rimando AM, Lee HJ, Ji Y, Reddy BS, Suh N. Antiinflammatory action of pterostlbene is mediated through the p38 mitogenactivated protein kinase pathway in colon cancer cells. Cancer Prev Res, 2009; 2:650-7.

Poulose SM, Thangthaeng N, Miller MG, Shukitt-Hale B. Effects of pterostilbene and resveratrol on brain and behavior. Neurochem Int, 2015; 89:227-33.

Rauf A, Imran M, Butt MS, Nadeem M, Peters DG, Mubarak MS. Resveratrol as an anti-cancer agent: a review. Crit Rev Food Sci Nutr, 2018; 58:1428-47.

Rege SD, Geetha T, Griffin GD, Broderick TL, Babu JR Neuroprotective effects of resveratrol in Alzheimer disease pathology. Front Aging Neurosci, 2014; 6:218.

Remsberg CM, Yáñez JA, Ohgami Y, Vega-Villa KR, Rimando AM, Davies NM. Pharmacometrics of pterostilbene: preclinical pharmacokinetics and metabolism, anticancer, anti-inflammatory, antioxidant and analgesic activity. Phytother Res, 2008; 22:169-79.

Renaud SD, de Lorgeril M. Wine, alcohol, platelets, and the French paradox for coronary heart disease. Lancet, 1992; 339:1523-6.

Riche DM, McEwen CL, Riche KD, Sherman JJ, Wofford MR, Deschamp D, Griswold M. Analysis of safety from a human clinical trial with pterostilbene. J Toxicol, 2013; Article ID 463595: 5 p.

Rimando AM, Cuendet M, Desmarchelier C, Mehta RG, Pezzuto JM, Duke SO. Cancer chemopreventive and antioxidant activities of pterostilbene, a naturally occurring analogue of resveratrol. J Agric Food Chem, 2002; 50:3453-7.

Rimando AM, Nagmani R, Feller DR, Yokoyama W. Pterostilbene, a new agonist for the peroxisome proliferator-activated receptor $\alpha$-isoform, lowers plasma lipoproteins and cholesterol in hypercholesterolemic hamsters. J Agric Food Chem, 2005; 53:3403-7.

Rimando AM, Kalt W, Magee JB, Dewey J, Ballington JR. Resveratrol, pterostilbene, and piceatannol in Vaccinium berries. J Agric Food Chem, 2004; 52:4713-9.

Roberti M, Pizzirani D, Simoni D, Rondanin R, Baruchello R, Bonora C, Buscemi F, Grimaudo S, Tolomeo M. Synthesis and biological evaluation of resveratrol and analogs as apoptosis-inducing agents. J Med Chem, 2003; 46:3546-54.

Rossi M, Caruso F, Antonioletti R, Viglianti A, Traversi G, Leone S, Basso E, Cozzi R. Scavenging of hydroxyl radical by resveratrol and related natural stilbenes after hydrogen peroxide attack on DNA. Chem Biol Interact, 2013; 20:175-85.

Schoonen WM, Salinas CA, Kiemeney LAL, Stanford JL. Alcohol consumption and risk of prostate cancer in middle-aged men. Int J Cancer, 2005; 113:133-40.

Seshadri TR. Polyphenols of Pterocarpus and Dalbergia woods. Phytochemistry, 1972; 11:881-98.

Siemann EH, Creasy LL. Concentration of the phytoalexin resveratrol in wine. Am J Eno Vitic, 1992; 43:49-52.

Silva CG, Monteiro J, Marques RR, Silva AM, Martínez C, Canle M, Faria JL. Photochemical and photocatalytic degradation of transresveratrol. Photochem Photobiol Sci, 2013; 12:638-44.

Sobolev VS, Khan SI, Tabanca N, Wedge DE, Manly SP, Cutler SJ, Coy MR, Becnel JJ, Neff SA, Gloer JB. Biological activity of peanut (Arachis hypogaea) phytoalexins and selected natural and synthetic stilbenoids. J Agric Food Chem, 2011; 59:1673-82.

Sun AY, Simonyi A, Sun GY. The "French paradox" and beyond: neuroprotective effects of polyphenols. Free Radic Biol Med, 2002; $32: 314-8$

Szkudelski T, Szkudelska K. Anti-diabetic effects of resveratrol. Ann N Y Acad Sci, 2011; 1215:34-9.

Tastekin B, Pelit A, Polat S, Tuli A, Sencar L, Alparslan MM, Daglioglu YK. Therapeutic potential of pterostilbene and resveratrol on biomechanic, biochemical, and histological parameters in streptozotocininduced diabetic rats. Evid Based Complement Alternat Med, 2018; Article ID 9012352: $10 \mathrm{p}$.

Tellone E, Galtieri A, Russo A, Giardina B, Ficarra S. Resveratrol: a focus on several neurodegenerative diseases. Oxidat Med Cell Longevity, 2015; Article ID 392169:14 p

Timmers S, Auwerx J, Schrauwen P. The journey of resveratrol from yeast to human. Aging, 2012; 4:146-58.

Tou JC. Evaluating resveratrol as a therapeutic bone agent: preclinical evidence from rat models of osteoporosis. Ann N Y Acad Sci, 2015; 1348:75-85.

Tsai HY, Ho CT, Chen YK. Biological actions and molecular effects of resveratrol, pterostilbene and 3'-hydroxypterostilbene. J Food Drug Anal, 2017; 25:134-47.

Varoni EM, Lo Faro AF, Sharifi-Rad J, Iriti M. Anticancer molecular mechanisms of resveratrol. Front Nutr, 2016; 3:8.

Wang B, Liu H, Yue L, Li X, Zhao L, Yang X, Wang X, Yang Y, Qu Y. Neuroprotective effects of pterostilbene against oxidative stress injury: involvement of nuclear factor erythroid 2-related factor 2 pathway. Brain Res, 2016; 1643:70-9.

Wang P, Sang S. Metabolism and pharmacokinetics of resveratro and pterostilbene. BioFactors, 2018; 44:16-25.

Wang Q, Xu J, Rottinghaus GE, Simonyi A, Lubahn D, Sun GY, Sun AY. Resveratrol protects against global cerebral ischemic injury in gerbils. Brain Res, 2002; 958:439-47.

Williams LD, Burdock GA, Edwards JA, Beck M, Bausch J Safety studies conducted on high-purity trans-resveratrol in experimental animals. Food Chem Toxicol, 2009; 47:2170-82.

Zhao RZ, Liu S, Zhou LL. Rapid quantitative HPTLC analysis, on one plate, of emodin, resveratrol and polydatin in the Chinese herb Polygonum cuspidatum. Chromatographia, 2005; 61:311-4.

How to cite this article:

Chan EWC, Wong CW, Tan YH, Foo JPY, Wong SK, Chan HT. Resveratrol and pterostilbene: A comparative overview of their chemistry, biosynthesis, plant sources and pharmacological properties. J Appl Pharm Sci, 2019; 9(07):124-129. 